DEBORAH HART AND JILL PHILLIPSON

\title{
Commentary: Is psychiatry media-friendly?
}

We would fully support Raj Persaud's contention that "psychiatry is a complex enterprise". Having been involved in the setting up and development of the College's press office over the last 12 years, we are still sometimes surprised at how complicated and unexpected some psychiatric issues are and the breadth of the topics which we are invited to comment on.

There are, however, certain misconceptions in Persaud's article which need to be addressed. First, he suggests that "media lobbying could become a more central role of the College". The College is not, and never could be, a lobbying organisation. It is a professional, educational and democratic organisation with a membership in excess of 10000 psychiatrists. The College's raison d'être is to promote good standards of practice in service provision, in education and in research and "to further public education therein". Much of this work is done through the press office by actively promoting College policy and new research findings. By definition, the College has to consult with, and reflect the interests of its members. Unlike a lobbying group, it is not a 'single issue' organisation, but represents a 'broad church' and a very wide range of complex topics.

Second, Persaud states that "It is complacent for professionals used to wielding authority from the comfort of their institutions to simply scorn the media". We believe that journalists who work with the College (and there are many) would find that statement difficult to comprehend. Far from scorning the media, we are keen to work positively with it. We undertake a structured programme of media activity, which is sufficiently flexible to be proactive, reactive and also to take advantage of ad hoc developments.

Psychiatrists, as well as journalists, have considerable presssure on their time. Yet for many years, our press office has had a database of more than a hundred members (many of whom have been media-trained) willing to work in a positive and constructive manner with the media, within the confines of their professional activities. Luckily for their patients, the majority of our members regard their care and treatment as paramount; but this does not mean that our spokespeople are unavailable to the media, nor do they "persist with a negative attitude towards media liaison".
We would be the last to deny that there is stigma surrounding psychiatry and psychiatrists. This is an important issue for the College which is being addressed by the five-year 'Changing Minds' campaign. We do need to recognise that this stigma will not easily be eradicated and is not helped by a vocal and angry minority of users calling for the abolition of electroconvulsive therapy (ECT) and other psychiatric practices, as Dr Persaud will have experienced at a recent public debate on ECT at the Institute of Psychiatry.

He contends that "the image of a profession, in particular the way the media handles it, should not be dismissed . . . as a trivial and remote issue". The press office has a vital role to play in the College's day-to-day activities. Why would it have invested in such a department for the last 12 years if it took the view that media relations are either trivial or remote?

Responding to media enquiries is one of our priorities, but the College has never been seen as 'rent-aquote' - quite the contrary. Some issues may be more relevant to psychology than to psychiatry; others may be too deep or complex for the College to be involved with, for example, in some of the more trivial talkshows. Other issues may require consultation with relevant Members or Officers of the College on how best to respond (e.g. revalidation issues), or may be politically sensitive (e.g. responding to the Home Secretary's pronouncements on dangerous, severe personality disorder). However, it is not the role of the College to react in a knee-jerk manner to all government or other statements on mental health issues. Sometimes the wisest counsel may be to remain silent.

For many years psychiatry has been faced by a powerful anti-psychiatry lobby which has used the media very effectively. However, following the Bristol affair and the Shipman case, psychiatry is no longer the only speciality in the firing line. In fact, doctors in general, social workers and teachers have all recently had their turn in the spotlight. Although psychiatry may have had its ration of negative media coverage over many years, there are lessons now which these other specialties and professions may have to learn from us.

*Deborah Hart Head of External Affairs, Jill Phillipson External Public Relations Advisor, External Affairs Department, Royal College of Psychiatrists, 17 Belgrave Square, London SW1X 8PG 